\title{
INSERÇÃO INTERNACIONAL: FORMAÇÃO DE CONCEITOS BRASILEIROS ${ }^{1}$
}

\author{
Diego Marques Morlim Pereira ${ }^{2}$
}

Em Inserção internacional: formação de conceitos brasileiros, o professor Amado Cervo aborda a inserção do Brasil no mundo, ligando teorias às práticas da política externa brasileira, com o objetivo de possibilitar ao seu leitor a compreensão das causalidades que afetaram a política externa nacional durante a história, assim como sua avaliação atual e suas perspectivas. Para tanto, Cervo divide seu livro em capítulos que discutem: os paradigmas da inserção internacional do Brasil; as transições políticas e seus reflexos para a política externa brasileira; as relações do Brasil com as organizações internacionais, com parceiros tradicionais e com novos parceiros, assim como as relações do país em seu contexto regional.

A primeira discussão abordada no livro são as tendências do pensamento brasileiro aplicado às relações internacionais. Segundo Cervo, no Brasil acumulou-se sólido pensamento sobre as relações internacionais que, no entanto, não evoluiu para teorização na disciplina. Em sua evolução, desde 1950, o pensamento brasileiro revela dois traços característicos: (i) vinculação com teorias latino-americanas e (ii) o desenvolvimento como problema epistemológico central.

A primeira fase da evolução do pensamento brasileiro em relações internacionais se deu com a CEPAL. Com expoentes em Raúl Prebisch e Celso Furtado, entre outros, a

\footnotetext{
1 CERVO, Amado. Inserção internacional: formação de conceitos brasileiros. São Paulo: Saraiva, 2008. ISBN 978-85-02-06570-3

${ }^{2}$ Mestrando no Programa de Mestrado Acadêmico em Relações Internacionais da Pontifícia Universidade Católica de Minas Gerais. E-mail: diegomorlim@yahoo.com.br
} 


\section{Conjuntura Austral}

CEPAL elaborou consistente crítica à teoria clássica de David Ricardo sobre vantagens do comércio internacional, ao afirmar que a especialização da produção em bens cujos custos de oportunidade fossem menores, ou seja, que tivessem menor custo de produção, geraria aumento da assimetria entre centro e periferia. Além disso, pautada na experiência brasileira das décadas de 1930 e 1940, a CEPAL passou a defender o paradigma desenvolvimentista em política exterior como forma de superar as desigualdades inexoráveis entre países desenvolvidos e subdesenvolvidos. O paradigma desenvolvimentista manter-se-ia por 60 anos no ideário nacional, tendo chegado ao fim com a abertura econômica promovida por Collor de Mello.

Por não obter adesão completa dos países latino-americanos, o paradigma desenvolvimentista foi questionado e deu origem à teoria da dependência, cujo principal pensador é Fernando Henrique Cardoso. Considerada uma evolução do pensamento cepalino, a teoria da dependência vincula-se ao pensamento marxista ao afirmar que o subdesenvolvimento perdurará enquanto houver exploração de Estados pobres por Estados ricos, em uma relação de dominação e dependência. Nesse sentido, a inteligência nacional, em vários momentos, durante a segunda metade do século XX, se relacionava com o mundo desenvolvido ora recorrendo aos seus recursos, como durante o governo JK e o governo Geisel, ora questionando a dependência externa, como nos episódios de default da dívida externa de 1943 e 1989.

Na década de 1990, surge o neoliberalismo, que propõe novo modelo de inserção do Brasil e de outros Estados latino-americanos no mundo. O neoliberalismo substitui a perspectiva estruturalista tradicional e enfatiza a cooperação devido à interdependência e à globalização verificadas naquele momento. Os neoliberais propunham o abandono do intervencionismo estatal e a abertura dos países periféricos à economia global. Foi o que ocorreu no Brasil nos governos de Collor de Mello, Itamar Franco e Fernando Henrique Cardoso. A diminuição do papel do Estado nos países latino-americanos, na década de 1990, levou, contudo, ao aumento das desigualdades e ao fracasso do paradigma neoliberal.

Criticado por acadêmicos e pela opinião pública em geral, o paradigma neoliberal ruiu e abriu possibilidade para a retomada do desenvolvimentismo nos países 


\section{Conjuntura Austral}

latino-americanos, no século XXI. Nesse sentido, o pensamento cepalino e dependentista ganha força, e a diplomacia brasileira, por intermédio de Celso Amorim, sugere agrupamentos de geometria variável para que os países em desenvolvimento possam superar as assimetrias que os afasta do desenvolvimento. Desta forma, não só o Estado passou a atuar mais ativamente para promover o desenvolvimento, no que se conhece por Estado logístico, como também as iniciativas de concertação entre os países tornaram-se prioridades, como se verifica, na América do Sul, com o fortalecimento do MERCOSUL e a criação da UNASUL.

Cervo ainda lembra que, entre o século XIX e o ano de 1930, o Brasil adotou o que se pode denominar de paradigma liberal-conservador de inserção internacional. Antes de o paradigma desenvolvimentista ganhar corpo, o Brasil atuava internacionalmente por meio de modelo definido pelos Europeus, que se pautava em abertura ao comércio internacional por imposição externa. O contexto era de mercantilismo e de clara exploração da periferia pelo centro capitalista. A face liberal explica a assinatura dos tratados desiguais e, depois deles, a política aduaneira, ou seja, o fato de ao Brasil ter-se estabelecido a condição periférica de modo permanente. A face conservadora explica o malogrado projeto de industrialização dos anos 1840, a determinação de exercer certo controle sobre o subsistema platino de relações internacionais e a negociação firme das fronteiras do território nacional.

Antes de discutir empiricamente a inserção do Brasil no mundo, Cervo traça o perfil da política externa brasileira, seus conceitos e princípios, assim como argumenta pela continuidade histórica da atuação exterior do Brasil devido, principalmente, ao respeito àqueles princípios e à atuação do Itamaraty. De acordo com Cervo, a política externa brasileira tem como princípios norteadores a tradição; a defesa de princípios, da cooperação, do multilateralismo; a independência, o realismo e o pragmatismo. Esses princípios da inserção internacional do Brasil perpassam alterações de governos e regimes e, mesmo em casos de ruptura institucional, como ocorrido em 1964, continuam norteando a atuação externa do Brasil. Vale lembrar que alguns desses princípios que o Brasil respeita em suas relações internacionais estão elencados explicitamente no Artigo $4^{\circ}$ da Constituição Federal de 1988. 


\section{Conjuntura Austral}

A atuação do Brasil na ONU, na OMC e em conferências internacionais, portanto, segue historicamente os preceitos defendidos pela política externa brasileira. Dessa feita, na ONU, o Brasil busca tradicionalmente a resolução pacífica de conflitos e a não intervenção. Mais recentemente, há o intuito da política externa pátria em vincular, de forma mais assertiva, o desenvolvimento à segurança. Na OMC, há esforço para redução das assimetrias entre ricos e pobres. Por meio das coalizões de geometria variável, os países em desenvolvimento passaram, desde 2001, a conseguir influenciar em debates antes pautados pelos interesses dos EUA e de países europeus. Assim como nas organizações internacionais, em conferências internacionais a atuação brasileira é embasada em um dos principais pilares da política externa brasileira durante a história: a defesa do multilateralismo.

Houve, claramente, objetivos e resultados distintos, nas quatro fases do multilateralismo defendido pelo Brasil: (i) contribuição do Brasil à construção do sistema internacional pós-guerra, que se vincula a uma política de prestígio; (ii) esforço despendido para reformar a ordem internacional dos anos 1960-1980, que objetiva à diminuição das assimetrias entre desenvolvidos e subdesenvolvidos, como se pode observar na participação destacada do Brasil na II UNCTAD (1967); (iii) perspectiva de atuar no sistema ao invés de reformá-lo, entre 1990-2002, quando o Brasil passa a ser protagonista nas conferências internacionais, como a CNUMAD (1992) e a Conferência de Viena (1993), e na Rodada Doha, na OMC; (iv) objetivo de estabelecer a reciprocidade entre estruturas hegemônicas e países emergentes, desde 2003, com a maior inserção internacional por meio de agrupamentos como MERCOSUL, UNASUL, IBAS, BRICS, G-20 e BASIC, e maior influência dos países em desenvolvimento, e sobretudo do Brasil, em diversas agendas das relações internacionais.

Nesse contexto, a formação do pensamento integracionista no Brasil e na América do Sul, segundo Cervo, se deve à ideia de se impor limites à globalização por intermédio do fortalecimento e da institucionalização de grupos de países que se privilegiam entre si. O modelo de integração sul-americano foi concebido durante o paradigma desenvolvimentista, por homens de Estado que concebiam a integração como meio para o desenvolvimento. A integração sul-americana, para o autor, se mostrava 


\section{Conjuntura Austral}

difícil, pois condicionamentos internos e regionais apresentam-se como obstáculos a superar. Entre esses condicionamentos, Cervo aponta as rivalidades regionais, a internalização dos conceitos cepalinos - que pregavam o fortalecimento do mercado interno para gerar o desenvolvimento e que constrangiam eventual processo de integração - e o receio dos outros países da região em relação ao Brasil, devido ao pensamento de que a integração perpetuaria sua posição de destaque na região. A consolidação do MERCOSUL e a constituição da UNASUL, todavia, atestam para a efetividade deste modelo de inserção internacional. O pensamento integracionista baseado na institucionalização de grupos de países que se privilegiam entre si pode ser, também, relacionado aos esforços contemporâneos de alavancar a cooperação sul-sul.

Passando da economia à segurança, Cervo afirma que a inserção internacional de segurança do Brasil esteve visceralmente vinculada à política exterior: até 1989, pela via do chamado projeto nacional, o qual estabelecia objetivos permanentes e supunha o planejamento estratégico; desde 1990, pela via da segurança multilateralizada, quando planejamento e projeto foram proscritos do vocábulo dos dirigentes e a política exterior perdeu autonomia decisória; e no presente, formulando-se questões cruciais acerca da segurança, as quais vão muito além de seu aspecto militar. A relação entre segurança, defesa e política externa é histórica: no Império houve decisões da pasta de Negócios Estrangeiros por intervenções na região do Prata contra pretensões expansionistas do Vice Reino do Prata (atual Argentina); na República Velha, as questões de segurança ligaram-se à política interna, com a contenção do tenentismo; na Era Vargas, a segurança foi relacionada fortemente com o desenvolvimento, o que gerou ganhos para a economia nacional mediante a atuação externa do Brasil; na nova República, houve subordinação aos ideais de segurança dos EUA na perspectiva de novos ganhos econômicos para o país; no Regime Militar a relação é explicita com a Doutrina de Segurança Nacional; com a redemocratização, o Brasil passa a atuar mais ativa e altivamente para vincular segurança a desenvolvimento e para dar às discussões de segurança um arcabouço multilateral e, portanto, legítimo.

No que diz respeito às relações do Brasil com parceiros tradicionais e com novos parceiros, Cervo faz uma abordagem histórica da evolução dessas relações e define que 


\section{Conjuntura Austral}

EUA e Europa consistem em parceiros tradicionais do Brasil, com os quais o país tem laços históricos que passam de dependência à coordenação. Cervo escreve um capítulo à parte sobre as relações Brasil-Rússia, uma vez que considera que os paradigmas de políticas externas dos dois países se encontraram nos anos 2000 sob as presidências de Lula e Putin, respectivamente. Hodiernamente, por mais que a cooperação sul-sul esteja em alta e traga resultados positivos tanto economicamente quanto politicamente ao Brasil, EUA e Europa são parceiros que não devem ser deixados em segundo plano.

No que tange a novos parceiros, Cervo discute os históricos e traça oportunidades e desafios para as relações do Brasil com Japão, Índia e China, na Ásia, assim como na África e no Oriente Médio. Esses são mercados cujas relações com o Brasil são mais recentes, mas que merecem atenção especial. O Japão tem proximidade cultural e econômica com o Brasil, há coordenação em relação às posições quanto à reforma do Conselho de Segurança da ONU e possibilidade de incrementos nos investimentos mútuos. A Índia é um parceiro político importante, com o qual o Brasil negocia conjuntamente no âmbito de diversas agendas, como a econômica, a ambiental e a financeira, e com o qual existem muitas possibilidades de comércio e investimentos. A China tornou-se o principal parceiro econômico do Brasil na última década, superando os EUA, o que explica por si só a importância desse mercado para o Brasil. Na África e no Oriente Médio, o Brasil tem uma série de investimentos públicos e privados, assim como crescente comércio e concertação política e diplomática.

Cervo faz uma ampla e completa análise da inserção internacional do Brasil. O autor discute histórico, desafios e oportunidades das relações do Brasil com organizações internacionais, entorno regional, parceiros tradicionais e novos parceiros tendo as teorias brasileiras e latino-americanas de relações internacionais como pano de fundo e os paradigmas de política externa como variáveis de análise. Inserção internacional: formação de conceitos brasileiros é um manual de história e de análise de política externa de grande utilidade para estudiosos e interessados na atuação externa do Brasil.

Resenha recebida dia 05 de abril de 2013. Aprovado em 20 de abril de 2013. 